\title{
"Maloca": la casa sin divisiones. Aprendiendo junto al pueblo indígena Zoró la vivencia de la solidaridad y la promoción de los derechos de los pueblos "Maloca": the house without divisions. Learning along with the Zoró the experience of solidarity and promotion of the rights of peoples "Maloca": a casa sem divisões. Aprendendo pelo povo indígena Zoró a experiência de solidariedade e de promoção dos direitos dos povos
}

DOI: http://dx.doi.org/10.15359/siwo.8-1.2

Nelise Wielewsky Narloch*

nelisesm20@gmail.com

Recibido: 09 de setiembre de 2014

Aprobado: 27 de enero de 2015

\section{Resumen:}

Este trabajo es parte de la sistematización de la experiencia de la autora junto al pueblo indígena Zoró, ubicado en la región amazónica brasileña. Además de compartir los aprendizajes de esta experiencia, desde este trabajo se busca construir una teoría sobre la solidaridad y los derechos humanos. Para esto se discute la teoría de Lévinas y Rorty acerca de la noción de solidaridad. El tema de los derechos humanos y de los pueblos, será fundamentado con la teoría de Gallardo, confrontada con la experiencia vivencial junto al pueblo Zoró. El aprendizaje expresado en este documento parte principalmente de experiencias de vida, estructuradas en la teoría y el rigor académico.

Palabras clave: Misión cristiana, Solidaridad, Derechos Humanos, Vida religiosa

\begin{abstract}
:
This work is part of the systematization of the author's experience with the Zoró, an indigenous people located in the Brazilian Amazon region. In addition to sharing the lessons learned from this experience, this paper seeks to build a theory of solidarity and human rights. For this, theories of Levinas and Rorty about the notion of solidarity are discussed. The discussion
\end{abstract}

on human rights and peoples' rights will be based on Helio Gallardo's theory (confronted with the life experience with the Zoró). Learning expressed in this document mainly emerges from life experiences formed at the theory and academic rigor.

Keywords: Christian Mission, Solidarity, Human Rights, Religious Life

\section{Resumo:}

Este trabalho faz parte da sistematização de uma experiência da autora com o povo indígena Zoró, residente na região amazónica brasileira. Além de partilhar a aprendizagem desta experiência, este trabalho pretende construir uma teoria sobre a solidariedade e os direitos humanos. Para isso, se abre a discussão da teoria de Lévinas e Rorty sobre a noção de solidariedade. O tema dos direitos humanos e dos povos será fundamentado pela teoria de Gallardo, confrontada com a experiência vivencial com o povo Zoró. O que se aprendeu, expressado nesse documento, parte principalmente de vivencias, estruturada na teoria e no rigor acadêmico.

Palavras chave: Missão cristã, Solidariedade, Direitos Humanos, Vida religiosa

* La autora es actualmente educadora en el Colegio Saint Francis, San José, Costa Rica. Tiene una maestría en sicopedagogía y durante varios años trabajó con el pueblo Zoró, en la Amazonia brasileña. 


\section{Introducción}

Personas en comunidades religiosas realizan muchas y diversas experiencias de misión entre pueblos y comunidades originarias. Las experiencias son, por su propia naturaleza, subjetivas, por personales que sean; cada experiencia resulta en un aprendizaje. La misión se expresa en encuentros, los encuentros nos mueven y conmueven, provocan cambios y rupturas. Este es el objetivo de este trabajo de sistematización: reconocer los aportes y aprendizajes que fueron obtenidos con el pueblo Zoró. Este artículo recoge la experiencia de la autora de encuentro con ese pueblo amazónico.

Para llevar a cabo esta sistematización, el presente escrito fue construido en cuatro partes. La primera parte, "La puerta de entrada: ser misionera católica", se presenta como la forma que se dio el contacto con el pueblo Zoró. Entre los diversos campos de trabajo pastoral realizados por la congregación católica femenina Marista, el trabajo junto a los pueblos indígenas fue el de mi interés. Esta fue la condición de entrada para esta experiencia de misión entre los Zoró.

La segunda parte consistió en “Aprender y desaprender". Para trabajar con los pueblos indígenas, uno de los requisitos es tener una formación y sensibilidad previa: cultura, contexto histórico y social, o sea, se aprende a ser misionera. Sin embargo, al momento de iniciar el trabajo misionero, las circunstancias concretas de la realidad obligan a desaprender muchas de las ideas preconcebidas y a construir nuevos aprendizajes, a partir del contacto y de la experiencia.

El centro de este trabajo es la tercera parte: "La maloca como metáfora de aprendizaje". La maloca es el nombre dado al lugar de habitación de las familias Zoró. Este lugar es de forma circular, compuesto por la puerta y las paredes de paja. Dentro conviven varias familias, cada una ubica sus hamacas alrededor del fuego. En su interior no existen divisiones, es un lugar que permite la interacción entre las personas y las familias, allí se expresa la convivencia en torno al fuego unifamiliar. La maloca es una expresión del universo y de la cosmovisión Zoró. La imagen de la maloca constituye el símbolo alrededor del cual se construye la noción de solidaridad.

"Las paredes de la maloca" simbolizan la estructura que da soporte a los derechos de los pueblos, es el tema de la cuarta parte de este trabajo. El pueblo Zoró, como todos los pueblos originarios de América, a partir de la colonización tuvieron sus derechos elementales violentados; la amenaza de exterminio fue constante en su historia y todavía hoy estas amenazas siguen presentes, de formas más disimuladas y revestidas de "buenas acciones y asistencialismo". ¿Cómo ser misionera cristiana y al mismo tiempo posicionarse ante la promoción del derecho de los pueblos originarios? ¿Son tareas separadas o constituyen el fundamento de la misión? Esta es una, entre muchas otras cuestiones, planteadas en la última parte de este trabajo.

A título de conclusión, lo que se pretende reflejar son algunos de los aprendizajes de esta experiencia de misión, teniendo conciencia de que el tema no está terminado, sino que hay continuidad porque el aprendizaje es comprendido dentro de un proceso continuo y permanente. 
"Maloca": la casa sin divisiones. Aprendiendo junto al pueblo indígena Zoró la vivencia de la solidaridad y la promoción de los derechos de los pueblos

"Maloca": the house without divisions. Learning along with the Zoró the experience of solidarity and promotion of the rights of peoples

"Maloca": a casa sem divisões. Aprendendo pelo povo indígena Zoró a experiência de solidariedade e de promoção dos direitos dos povos

Nelise Wielewsky Narloch

\section{La puerta de entrada: ser misionera católica}

Entre los años 1997 y 2001 tuve la oportunidad de hacer una experiencia de misión junto al pueblo indígena Zoró, localizado en la amazonia brasileña, específicamente al norte del estado de Rondonia.

Por diez años fui misionera católica, perteneciente a la congregación de las Hermanas Maristas ${ }^{1}$. Después de cierto tiempo de formación, las postulantes que deciden consagrarse a esta vocación religiosa deben formalizar su opción con los tres votos religiosos ${ }^{2}$, conforme menciona Robert (1): pobreza, castidad y obediencia. Como religiosa consagrada dentro de la congregación de las Hermanas Maristas, mi vida estaba llamada a ser vivida en la perfección de la caridad ${ }^{3}$, a poner a Cristo en el centro mi existencia. Esta es la vocación al seguimiento de Jesús en la vida religiosa católica.

Cuando una mujer opta por la vida consagrada, se utiliza la metáfora de ser esposa de Jesús Esto significa que la misión de una monja será vivir entre la contemplación y la misión, siempre modelada por la propia vida de Cristo en este mundo ${ }^{4}$ (Robert 3). La contemplación se vive en los momentos de oración comunitaria, en los retiros espirituales y la eucaristía. La misión ${ }^{5}$ hace parte de la dimensión apostólica de los votos, que son cumplidos de acuerdo a la necesidad de cada lugar de misión.

En Brasil las Hermanas Maristas trabajan en diferentes áreas de misión. El trabajo misionero ${ }^{6}$ al que se dedican

1 Las Hermanas Maristas forman parte de una orden religiosa Católica. La congregación fue fundada en Fouvière, Lyon, Francia, 1816 por el Padre Jean Claude Colin y Jeanne-Marie Chavoin. Actualmente están presentes en 8 países, trabajando con poblaciones marginadas de la sociedad, en el área de la educación, salud, cuidado con el medio ambiente. Las áreas de misión son varias, dependiendo de la necesidad de cada país en donde están presentes.

2 Robert afirma que "Los tres votos de religión componen lo esencial de toda vida religiosa" (1).

3 De acuerdo con la Suma Teológica de Tomás de AQUINO: "Por sí misma y esencialmente, la perfección de la vida cristiana consiste en la caridad, principalmente en el amor a Dios, después, secundariamente, en el amor al prójimo, amores a los que se refieren los principales preceptos de la Ley divina. Ahora bien, es importante señalar que el amor a Dios y al prójimo no caigan sobre el precepto siguiendo solo una medida limitada, siendo la demasía simplemente un consejo. (...) "La caridad es el fin mismo del precepto" como dice san Pablo. Ahora bien, cuando se trata del fin, no se pueden guardar medidas. (...) La perfección consiste esencialmente en los preceptos. (Robert 1)

4 "A imagen de Cristo, cuya identidad de Hijo bien amado es al mismo tiempo la de Enviado del Padre, es la relación a Dios que envía a todo cristiano al mundo: recibiendo con el Hijo y en el Espíritu el movimiento de amor del Padre, somos enviados. Ahí está el vínculo entre contemplación y misión: la primera no está separada de la vida apostólica, ya sea precediéndola o siguiéndola." (Robert 3).

5 El concepto de misión desde la perspectiva de los votos consagrados son tomados del documento Redemptoris Misio \# 31: "el Señor Jesús envió a sus Apóstoles a todas las personas y pueblos, y a todos los lugares de la tierra. Por medio de los Apóstoles la Iglesia recibió una misión universal, que no conoce confines y concierne a la salvación en toda su integridad, de conformidad con la plenitud de vida que Cristo vino a traer (cf. Jn 10,10); ha sido enviada 'para manifestar y comunicar la caridad de Dios a todos los hombres y pueblos"”.

6 “Jesús salió al encuentro de personas en situaciones muy diversas: hombres y mujeres, pobres y ricos, judíos y extranjeros, justos y pecadores..., invitándolos a todos a su seguimiento. Hoy sigue invitando a encontrar en El el amor del Padre. Por esto mismo el discípulo misionero ha de ser un hombre o una mujer que hace visible el amor misericordioso del Padre, especialmente a los pobres y pecadores". Documento de Aparecida \#147. 
las Hermanas Maristas ${ }^{7}$ en la Amazonia brasileña, junto a los pueblos indígenas, se denomina específicamente misión ad gentes ${ }^{8}$. A través de un discernimiento personal y con la orden religiosa, fui enviada formar parte de una comunidad de 3 hermanas para trabajar en la misión ${ }^{9}$ con el pueblo indígena Zoró. En forma más puntual, mi condición de entrada a esta experiencia de misión con los Zoró fue:

1. Tengo una identidad religiosa Marista

2. Pertenezco a una estructura religiosa católica

3. Soy formada bajo el paradigma de misión según los criterios de la iglesia católica apostólica romana.

4. Estoy condicionada a mis tres votos religiosos: pobreza, castidad y obediencia.

5. Voy comprometida con la misión ad gentes, con una agenda de trabajo bajo los criterios de esta misión.

La puerta de entada para la experiencia de misión junto al pueblo Zoró fue ser misionera Marista. Probablemente sin esta condición yo no habría tenido la posibilidad de entrar en contacto y convivir con este pueblo durante cinco años de mi vida como misionera.

\section{Aprender y desaprender}

Son muchas las instituciones que trabajan con los pueblos indígenas, organizaciones no gubernamentales, iglesias, órganos gubernamentales entre otros. El contacto oficial con cualquiera de las comunidades tiene que darse a través de una de estas entidades. Por supuesto que hay grupos que no pertenecen a ninguna de estas instituciones y que tienen objetivos claros en sus relaciones con los indígenas amazónicos: la extracción del caucho, el robo de la madera, las investigaciones de la biodiversidad y medicina tradicional.

El vínculo de acceso entre las personas misioneras religiosas (tanto católicas como de otras denominaciones)

7 Somos llamadas a acompañar a las personas que tienen sed de sentido en sus vidas. “.... vivimos en cualquier lugar donde podemos prestar nuestro servicio, sin buscar ni la estima ni el reconocimiento" (Constituciones Maristas número 6)

8 La actividad misionera específica, o misión ad gentes, tiene como destinatarios "a los pueblos o grupos humanos que todavía no creen en Cristo", "a los que están alejados de Cristo", entre los cuales la Iglesia "no ha arraigado todavía", y cuya cultura no ha sido influenciada aún por el Evangelio. Esta actividad se distingue de las demás actividades eclesiales, porque se dirige a grupos y ambientes no cristianos, debido a la ausencia o insuficiencia del anuncio evangélico y de la presencia eclesial. Por tanto, se caracteriza como tarea de anunciar a Cristo y a su Evangelio, de edificación de la Iglesia local, de promoción de los valores del Reino. La peculiaridad de esta misión ad gentes está en el hecho de que se dirige a los "no cristianos". Por tanto, hay que evitar que esta «responsabilidad más específicamente misionera que Jesús ha confiado y diariamente vuelve a confiar a su Iglesia» se vuelva una flaca realidad dentro de la misión global del Pueblo de Dios y, consiguientemente, descuidada u olvidada. Redemptores Missio \#34

9 El documento de Santo Domingo (\#243) incorpora el término inculturación a la misión ad gentes. Sin embargo sigue enfatizando el concepto de misión a través de la Evangelización inculturada, que será siempre la salvación y liberación integral de un determinado pueblo o grupo humano, que fortalezca su identidad y confíe en su futuro específico, contraponiéndose a los poderes de la muerte, adoptando la perspectiva de Jesucristo encarnado, que salvó al hombre desde la debilidad, la pobreza y la cruz redentora. 
"Maloca": la casa sin divisiones. Aprendiendo junto al pueblo indígena Zoró la vivencia de la solidaridad y la promoción de los derechos de los pueblos

"Maloca": the house without divisions. Learning along with the Zoró the experience of solidarity and promotion of the rights of peoples

"Maloca": a casa sem divisões. Aprendendo pelo povo indígena Zoró a experiência de solidariedade e de promoção dos direitos dos povos

y los pueblos indígenas es el Consejo Indigenista Misionero (CIMI). Una de las características del CIMI ${ }^{10}$ es la intención de NO evangelizar a los pueblos indígenas que forman parte del grupo de misión, sino ser una presencia de solidaridad, participación y énfasis en la autonomía e integridad de cada pueblo. Iluminados por la perspectiva de misión en el documento de Santo Domingo en 1992, donde la Iglesia aceptó el reto de "profundizar un diálogo con las religiones no cristianas presentes en nuestro continente, particularmente las indígenas y afroamericanas, durante mucho tiempo ignoradas o marginadas", y se comprometió con los pueblos indios a "acompañar su reflexión teológica, respetando sus formas culturales que les ayudan a dar razón de su fe y esperanza" (\#248).

Hasta entonces yo traía conmigo toda mi formación en misión bajo los criterios mencionados anteriormente, condicionada por las directrices de la iglesia local; en otras palabras, yo venía con el sueño romántico y la mentalidad clásica de alguien que quiere llevar la "Buena noticia del evangelio a todos los pueblos" (Mt 16). El primer desencuentro ocurrió al darme cuenta que la visión de misión del CIMI ${ }^{11}$ era diferente de la que yo traía en mi formación.

Aunque sea un órgano vinculado a la CNBB (Conferencia Nacional de Obispos de Brasil), en su trabajo misionero dio un nuevo significado a la obra de la Iglesia Católica con los pueblos indígenas. Una de las propuestas fundamentales consistió en fomentar la reconciliación entre las personas y los pueblos, la promoción de asambleas indígenas, para garantizar sus derechos fundamentales como una forma de saldar la deuda histórica con los pueblos originarios. Todo esto encaminado hacia el reconocimiento de la diversidad cultural del país.

Amparada por esta institución, organizada en el ámbito nacional ${ }^{12}$, recibí una nueva formación en el área

10 "O Cimi é um organismo vinculado à CNBB (Conferência Nacional dos Bispos do Brasil) que, em sua atuação missionária, conferiu um novo sentido ao trabalho da igreja católica junto aos povos indígenas". Criado em 1972, quando o Estado brasileiro assumia abertamente a integração dos povos indígenas à sociedade majoritária como única perspectiva, o Cimi procurou favorecer a articulação entre aldeias e povos, promovendo as grandes assembléias indígenas, onde se desenharam os primeiros contornos da luta pela garantia do direito à diversidade cultural.

Os princípios que fundamentam a ação do Cimi são:

- o respeito a alteridade indígena em sua pluralidade étnico-cultural e histórica e a valorização dos conhecimentos tradicionais dos povos indígenas;

- o protagonismo dos povos indígenas, sendo o Cimi um aliado nas lutas pela garantia dos direitos históricos;

- "a opção e o compromisso com a causa indígena dentro de uma perspectiva mais ampla de uma sociedade democrática, justa, solidária, pluriétnica e pluricultural”. Conforme al sitio oficial del CIMI http://www.cimi.org.br/site/pt-br/

11 O objetivo da atuação do Cimi foi assim definido pela Assambléia Nacional de 1995: "Impulsionados(as) por nossa fé no Evangelho da vida, justiça e solidariedade e frente às agressões do modelo neoliberal, decidimos intensificar a presença e apoio junto às comunidades, povos e organizações indígenas e intervir na sociedade brasileira como aliados (as) dos povos indígenas, fortalecendo o processo de autonomia desses povos na construção de um projeto alternativos, pluriétnico, popular e democrático." Consultado en http://www.cimi.org.br/site/pt-br/index.php?system=news\&action=read\&id=4237 el 21 de julio del 2014.

12 Mais de 400 missionários, constituindo 112 equipes, convivem com o dia-a-dia dos povos indígenas em todo país. São leigos e religiosos que buscam com a presença solidária, o compromisso e o testemunho colocar-se a serviço da vida desses povos. Para articular, assessorar e orientar a ação desses missionários e para apoiar as lutas dos povos indígenas pela garantia de seus direitos, o Cimi organizou-se em 11 Regionais distribuídos pelo país e um Secretariado Nacional localizado em Brasília. Consultado en: http://www.cimi.org.br/site/pt-br/?system=paginas\&conteudo id=5687\&action=read 
misionera que me hizo deconstruir lo que traía por dentro y construir nuevos conceptos acerca de mi comprensión sobre la misión, sobre el diálogo y sobre la solidaridad. Compartir estos cambios radicales de paradigma, tiene un significado muy profundo en la comprensión de la alteridad presente en la otra persona. Por lo tanto, más que un aparato teórico, este artículo pretende compartir la experiencia de cambio de mentalidad, cambio de proceso, cambio de paradigma y todo el aprendizaje que viene como consecuencia.

\section{La maloca como metáfora del aprendizaje}

Los Zoró conviven dentro de una gran maloca ${ }^{13}$ sin paredes, donde cada familia tiene su fuego, sus hamacas, sus ollas. Pero el espacio es común. No hay compartimentos privados o separados. Cada uno puede ver todo el espacio y todas las personas desde diferentes lugares y perspectivas. Esta metáfora de la casa sin divisiones internas hace parte de este proceso de aprendizaje. Antes mi perspectiva de misión era la de hacer conocer a Dios. Mi nueva formación de misión me hizo percibir que no hay que llevar a Dios. La presencia o la ausencia de Dios, que tiene muchos nombres y significados, está vivo en todas las culturas originarias.

La experiencia de estar dentro de una maloca y poder presenciar las interacciones humanas que se dan en su interior provocan en mí una serie de reflexiones acerca de la idea de cuidado y de pertenencia, sin embargo, lo que más me cuestiona es la idea de solidaridad. Al no haber divisiones geográficas o barreras internas, la imagen que representa estas interacciones es que todos forman parte de una gran familia humana, que se cuida mutuamente.

Parece que el concepto de solidaridad está en boga actualmente, esto es positivo y al mismo tiempo peligroso, porque corre el riesgo de ser banalizado. Truchero menciona que es "un término que goza de una presencia muy significativa en los medios de comunicación y el debate político en la mayoría de las sociedades actuales, especialmente en Europa. En un mundo cada vez más globalizado y más desigual, el discurso de la solidaridad está omnipresente" (386).

El principio de solidaridad es la convivencia comunitaria en el cuido y atención de los hijos e hijas. En una estructura comunitaria indígena, los hijos e hijas no pertenecen a sus padres, sino que son de todos, y esto implica que el cuidado, el amor, la atención y la formación es tarea de todos.

¿Tendría lugar esta concepción de solidaridad dentro de un contexto cultural occidental y además urbano? ¿Cómo conciliar o hacer compatible el individualismo y la propiedad privada con una sociedad solidaria? Esta

13 Lacerda describe la maloca de la siguiente manera: "Os Zoró se organizavam de forma que cada qual tenha o seu lugar definido. A Zap Puj Teré (casa Grande) ou maloca está organizada de forma que cada família se estabelece por ordem de poder e status. Existe a maloca do Zawijaj e a maloca do Wãwã. Há uma divisão virtual e uma organização dos espaços, o lugar da rede do Zawijaj e sua família as redes das outras famílias que coabitam com o Zawijaj e o lugar para a rede da visita". (Lacerda 223-224) 
"Maloca": la casa sin divisiones. Aprendiendo junto al pueblo indígena Zoró la vivencia de la solidaridad y la promoción de los derechos de los pueblos

"Maloca": the house without divisions. Learning along with the Zoró the experience of solidarity and promotion of the rights of peoples

"Maloca": a casa sem divisões. Aprendendo pelo povo indígena Zoró a experiência de solidariedade e de promoção dos direitos dos povos

Nelise Wielewsky Narloch

es una de las preocupaciones de Rorty ${ }^{14}$ que hace una aproximación muy original de la idea de solidaridad. El autor critica al liberalismo individualista afirmando que "la solidaridad es un contrapunto al "prejuicio egoísta"” (Camps 38) Para Rorty, mencionado por Camps:

La solidaridad es un sentimiento de compasión con aquellos que son "como nosotros", donde «nosotros» tiene un sentido propio y no equivale a "toda la humanidad", sino que depende de semejanzas y diferencias. Es decir, necesariamente implica un "ellos". La noción de solidaridad de Rorty por tanto, no es universal, sino circunscrita a aquellos con los que nos identificamos. ${ }^{15}$ (38)

Es reconocer a las personas como parte de nosotros, especialmente a las que de alguna forma tienen aspectos comunes, como por ejemplo, si soy madre, me identifico con las demás madres, los hijos e hijas de ellas también son mis hijos e hijas. Si me identifico como migrante, los demás migrantes también hacen parte del grupo de nosotros. De acuerdo con esta perspectiva de Rorty, la solidaridad se relaciona con la identificación de aspectos comunes, que nos hacen capaces de cohabitar en esta casa sin paredes.

Otro concepto de solidaridad que puede incurrir en el intento de aprender con la vivencia indígena de la maloca es presentada por Lévinas ${ }^{16}$, que enfatiza el otro a través de la mirada. De origen lituano y judío, marcado por su condición de migrante, fundamenta su teoría en la idea de que "lo existente, que da sentido a los entes en el mundo, produce una impersonalidad árida, neutra y sutil, que solo podría ser superada en el ser-para-el-otro, como momento ético de respeto a la Alteridad" (Aguirre y Jaramillo 9).

La idea que este autor manifiesta es que "la otra persona" debe ser reconocida como "otra" a través de la mirada. El pensamiento de Lévinas critica el principio de igualdad ${ }^{17}$ que existe en las instituciones y no permite ver a

$14 \quad$ Nacido el 4 octubre de 1931, en Nueva York, Richard Mckay Rorty es llamado el renovador de la filosofía estadounidense dentro de la corriente del neopragmatismo, en la que emprendió un revolucionario trabajo que insta a los filósofos a abandonar la búsqueda de verdades absolutas.

15 Rorty elabora una concepción de solidaridad propia, que no descansa en la participación de los individuos de una verdad o meta común sino que se construye a través del reconocimiento de la semejanza. La solidaridad se crea por medio de la capacidad imaginativa para ver a los extraños como compañeros de sufrimiento. Para Rorty, no hace falta encontrar una esencia común a la raza humana, la susceptibilidad de padecer dolor es un vínculo suficiente. La solidaridad es el reconocimiento de que las diferencias con otras personas son menos importantes que el deseo de evitar el dolor y el sufrimiento. Camps, 1990:38

16 Fue un importante filósofo y escritor. El magisterio de Lévinas permitió la difusión de la fenomenología alemana en Francia. A la manera de Paul Ricoeur y Jules Lasalle, Lévinas consagró su vida y su obra a la reconstrucción del pensamiento ético después de la Segunda Guerra Mundial. Natural de Lituania, desarrolló su trabajo en Francia e Italia, con breves estancias intelectuales en Austria. Es conocido por sus trabajos relacionados con la fenomenología, el existencialismo, la ética, la ontología y la filosofía judía. (Wikipedia)

17 “....al instaurarse instituciones que se fundamentaron en un principio de igualdad, en el primado de una razón "justa" que correspondiera a la cordura y al buen juicio, que superara los desmanes ocasionados por una irracionalidad fundada en un mundo mítico. Se empieza así a asistir a una fiesta de disfraces en la que cada participante moderno plantea su postulado formal (teorético), aduciendo que su propuesta de sociedad progresista es más acertada que la de sus coetáneos. La promesa de vivir en un mundo mejor hace que aceptemos la legalidad de que somos iguales; paradójicamente, no podemos aspirar a que el sujeto sea visto en su «verdad»". 
las personas tal y como son. Afirma que al aceptar al sujeto como totalidad ${ }^{18}$ se neutralizan las particularidades, se invisibiliza y reduce al otro como otro:

Así fue como las culturas occidentales-progresistas miraron aquellas obras que necesitaban de progreso, marginales en intelectualidad y conocimiento «científico»; primó una mono-cultura del saber en detrimento de saberes-otros que, sin lentes formales, veían y sentían la realidad de manera distinta" (Aguirre y Jaramillo 6).

La propuesta de Lévinas que me interesa enfatizar, porque de alguna forma responde a la pregunta de cómo, a partir de la experiencia con el pueblo Zoró, se puede aprender a ser solidario en la realidad urbana, viene del principio de poder ver a la otra persona como otra. La idea de poder mirar a la persona como otra hace que se escape del poder de quien la mira y permite ser ella misma. Esta idea rompe con la relación totalitarista, en el sentido de que, según Aguirre y Jaramillo, "ella rompe la vasija totalitaria del englobamiento que intenta apresar al Otro" (6).

Lo que rompe la totalidad del otro es la idea del infinito, expresada por Lévinas en las siguientes puntuaciones:

La exterioridad del Otro ya no es la ambigua exterioridad objetiva de la verificación; es relacional, es la exterioridad que rompe con la objetividad para colocarse en el plano de la trascendencia, del respeto y de la responsabilidad en la que se siente pasión (del verbo padecer) por el Otro, más allá de la imagen corporal con la que éste se presenta. Es una exterioridad que invoca a la trascendencia, a algo que sobrepasa el sentido fisiológico e ingresa a territorios donde se está co-implicado. (Aguirre y Jaramillo 9)

Tanto Rorty como Lévinas aportan conceptos teóricos claves de lectura que posibilitan aprendizajes significativos acerca de la solidaridad. De estos conceptos se generan apenas algunas pistas para el aprendizaje de la dimensión comunitaria de las comunidades indígenas en un mundo urbanizado. Sigue el desafío de pensar en cómo implantar estos aprendizajes dentro de un sistema educativo orientado hacia el trabajo dentro del mercado laboral capitalista y exclusivista.

El tema de la solidaridad es sumamente significativo dentro de esta experiencia de misión junto al pueblo Zoró porque implica replantear especialmente la dimensión intercultural, brutalmente diferente a la urbana. Entonces la solidaridad abarcaría aspectos de lo privado y lo público ${ }^{19}$ (conceptos urbanos y modernos, ver la

18 "La totalidad llega entonces a alienar la singularidad; la pone en relación con la obra, mas no con su ser en el mundo; la coloca en la pre-disposición de lo dicho y la aleja del acontecimiento, del ser tal y como se nos presenta, para poder captarlo sin más. Los lentes de la totalidad nos generan presbicia al ver un más allá teórico, distorsionado de lo físicamente visible. La singularidad deja de ser singular para volverse universal, para pensar aquello que los contenidos nos exigen considerar. La singularidad queda contenida en la caja de la razón universal y empieza a pasar de mano en mano, predispuesta a la obra, configurando la concretización del anonimato en la misma humanidad" (Aguirre y Jaramillo $6)$.

19 El liberalismo para Rorty constituye la forma de organización social que mejor se adapta a la contingencia y a la creciente diversidad de proyectos individuales o privados. 
"Maloca": la casa sin divisiones. Aprendiendo junto al pueblo indígena Zoró

la vivencia de la solidaridad y la promoción de los derechos de los pueblos

"Maloca": the house without divisions. Learning along with the Zoró the

experience of solidarity and promotion of the rights of peoples

"Maloca": a casa sem divisões. Aprendendo pelo povo indígena Zoró a expe-

riência de solidariedade e de promoção dos direitos dos povos

Nelise Wielewsky Narloch

casa sin divisiones), de lo propio y lo ajeno, de la apreciación del pasado y el presente contra la sobrevaloración del futuro.

Esta experiencia me hace pensar que, de un lado tenemos la experiencia de solidaridad de un grupo indígena que vive en el interior de la grande floresta amazónica, en el norte de Brasil. De otro lado tenemos la experiencia urbana de dos grandes teóricos que conceptualizan la solidaridad que nos mueve a la compasión y la mirada que nos permite ver al otro como tal. Entonces lo que para Rorty y Lévinas es descubrimiento, para los Zoró es la vida cotidiana.

Lo que estos dos autores dicen está implicado en la Maloca: es un espacio abierto y común, todo es común porque la vida es común. En las condiciones duras de la vida, lo común se torna solidaridad, porque es la forma de sobrevivir como personas y como colectividad. Por otro lado la Maloca permite extender la visión, la descompartimentaliza, la hace universal, se observa el universo desde cualquier punto de la casa y esa casa es el universo de seguridad y protección para todas las personas. En este sentido, cuidarse mutuamente no es una opción, es una manera de vivir.

¿Cuáles son las implicaciones de vivir en una casa compartida? La casa sin paredes y sin divisiones no esconde nada y pone en evidencia las cosas que abundan y las cosas que faltan: la abundancia y la carestía. Pone ante la mirada el sufrimiento y el amor de los que cohabitan en la casa.

En la casa sin paredes no hay espacios privados, ni para el sexo. En este espacio hasta la intimidad sexual hace parte también de la vida cotidiana, contradiciendo la costumbre occidental de separar la casa en cuartos y espacios privados. Parece que en una casa sin paredes la solidaridad no resulta algo extraño, porque está a la vista.

Los autores aportan elementos teóricos para comprender la solidaridad. Enfatizan que, desde el Occidente, para aprender, se compartamentaliza y se separa. Aquí, la propiedad privada y el capital juegan como elementos de autodestrucción. En los Zoró, la casa abierta supone el espacio de cuidado y protección. Desde la perspectiva de este grupo indígena, es una práctica de vida, una actitud existencial.

Este conocimiento de los Zoró es una sabiduría, y como sabiduría, se torna forma de vida. La casa común genera un cuidado común. La postura occidental genera un mercado de intereses propios, inhumano y especulativo, lucrativo para pocos. Es un mercado que también es destructivo de la naturaleza, porque cosifica y transforma todo en mercancía o producto. Para los Zoró, el cuidado; para el Occidente, el mercado. El cuidado genera vida, buen vivir. El mercado excluye al que no tiene poder de comprar; genera hambre, violencia, acumulación y exclusión.

La metáfora de la vida en la casa sin paredes, que es el estilo de vida de la casa común de los Zoró, tiene mucho que enseñar al Occidente. La solidaridad genera relaciones de más gratuidad. La ayuda mutua y la comprensión se dan de forma gratuita. En el Occidente las relaciones son más comerciales y competitivas, todo se compra, todo se vende y todo tiene un precio. Por lo tanto si tiene un precio, genera lucro. Son relaciones 
que destruyen el planeta, las vuelven insensibles a las necesidades, porque todo es por lucro. Al contrario, las relaciones solidarias funcionan más dentro del ámbito de la gratuidad.

\section{Las paredes que sustentan los derechos de los pueblos indígenas}

El relativo aislamiento del pueblo Zoró tuvo cambios por vuelta del siglo XIX; destaca Lacerda:

Esto sucedió cuando, aunado al proceso de expansión del mercado mundial del caucho, tuvo lugar la venida de los campesinos en búsqueda de nuevas tierras y la exploración del precioso líquido blanco. Este producto natural fue el motivo por el cual cada vez más personas se arriesgaban al interior de la selva amazónica, amenazando la paz y la integridad de las comunidades indígenas. ${ }^{20}(17)$

Investigaciones históricas afirman que en esta época cerca de 30 grupos indígenas nativos fueron aniquilados por causa de la extracción del caucho (Gomes Neves 3). La persecución deliberada, asociada con la esclavitud de los indígenas era costumbre en la época. Otro factor de interferencia y extinción de muchos grupos indígenas fue la construcción de la línea del telégrafo.

Una narración importante recopilada por Lacerda cuenta lo siguiente:

Os Zoró narram sua experiência de contato com os seringueiros e varias historias de vida entre elas duas histórias muito significativas: em resumo, a história de Sirigapip um Zoró que se torna amigo dos seringueiros, abandona seu povo para viver com estes. A história de Iti Sapepep, um guerreiro que perde sua mãe com uma enfermidade desconhecida e sai a procura do responsável pela doença e encontra o acampamento do homem branco e o mata. (18)

La convivencia con los nativos me permitió hacer diferentes reflexiones acerca del tema de los derechos de los pueblos, especialmente por ser también una de las banderas de lucha del CIMI. El motivo del interés por los derechos humanos y de los pueblos, tanto del CIMI como de otras organizaciones y movimientos en el ámbito de las iglesias, tiene sus razones históricas. ${ }^{21}$

El discurso actual de los derechos humanos (entendido en este trabajo desde los derechos de los pueblos originarios) tiene que ver con la modernidad y la ruptura de la tutela religiosa. Esto porque son una creación singular de la modernidad política, destinados a proteger ciertos derechos del individuo en cuanto ciudadano.

\section{Traducción propia.}

21 La presencia y significado del tema de los derechos humanos y su discusión actual en América Latina tiene un origen histórico político relacionado con la emergencia, más o menos paralela, de una serie de regímenes autoritarios que combinan, con sus diferencias y matices, la doctrina de seguridad nacional con políticas económicas de corte neoliberal. No puede afirmarse que estos derechos no hayan sido conocido antes o incorporado a algunas instituciones o declaraciones de principio en distintos países del continente, así como tampoco podría decirse que con anterioridad a los setenta fueron plenamente respetados. Quizá lo distinto resida en que el conjunto de esos nuevos regímenes llevó a cabo una política de violación sistemática de los derechos humanos, amparado algunas veces y aunque suene a paradoja, en su pretendida condición de defensores de los valores occidentales. (Salvat Boloña y Salas Astrain 135-152) 
"Maloca": la casa sin divisiones. Aprendiendo junto al pueblo indígena Zoró la vivencia de la solidaridad y la promoción de los derechos de los pueblos

"Maloca": the house without divisions. Learning along with the Zoró the experience of solidarity and promotion of the rights of peoples

"Maloca": a casa sem divisões. Aprendendo pelo povo indígena Zoró a experiência de solidariedade e de promoção dos direitos dos povos

Nelise Wielewsky Narloch

(Salvat Boloña y Salas Astrain 136) ¿Por qué en la edad media no se hablaba sobre los derechos humanos? Porque el cristianismo tenía una presencia en todos los campos, una omnipresencia. Es con el surgimiento de la separación de la religión del estado, separación de los poderes que surge una cultura de los derechos humanos. ${ }^{22}$

Existen diferentes acentos acerca de los derechos humanos, incluso diferentes teorías y conceptualizaciones que con diferentes énfasis. Así que se puede hablar sobre los derechos humanos enfatizando aspectos del derecho, como las leyes y los derechos privados de cada persona. Pero también se puede hablar sobre derechos humanos desde una comprensión antropológica, enfatizando lo humano presente en los derechos. En este caso no se aplicarían los derechos humanos solo como cuestiones legales, sino como experiencia de alteridad.

Helio Gallardo ${ }^{23}$ aborda el tema de los derechos humanos a partir de la teoría crítica ${ }^{24}$ : lo que plantea este autor como teoría crítica de los derechos humanos es el no posicionarse en relación con estos desde ninguna concepción de derecho natural..$^{25}$

En la versión moderna del derecho natural, los derechos humanos se siguen de una naturaleza humana, aunque el orden natural del mundo tenga también un papel en ellos. Esta naturaleza humana resulta de una apreciación de lo que serían los individuos con entera independencia de sus relaciones sociales. (Gallardo 40)

Desde esta perspectiva, la solidaridad no tiene espacio dentro de esta concepción del derecho natural, porque esta visión subraya la individualidad de cada persona y no su codependencia dentro de una sociedad.

Para los pueblos indígenas el concepto de "derecho natural" fue un engaño, primero por la dificultad de reconocerlos como personas y como comunidad; esto resultó en un atropello de sus derechos. Después por la incoherencia de que, aun siendo reconocidos teóricamente como personas y sujetos de evangelización, todavía en la práctica no se cumplen las leyes promulgadas para este reconocimiento. Desde una lectura crítica de la historia, para el pueblo indígena Zoró el derecho natural fue un abuso de poder por parte de los blancos con

22 Las personas tienen derechos por ser humanos, no importa si no son católicos, ni religiosos. Antes no había la figura de lo humano fuera del contexto religioso, como tenemos hoy. Se suponía que el cristianismo estaba presente en todos los campos y ámbitos de la vida pública y privada.

23 Helio Gallardo nació en Chile, 1942; es un filósofo y escritor chileno, profesor de la Universidad de Costa Rica (UCR), de la Universidad Nacional de Costa Rica (UNA) y de la Universidad Estatal a Distancia, conocido por sus estudios sobre la realidad social y la política popular en Latinoamérica.

24 Desde esta perspectiva, los derechos humanos deben considerarse como la puesta en práctica de disposiciones críticas con respecto al conjunto de posiciones desiguales que las personas y grupos ostentan tanto a un nivel local como global. Pero para ello o, en otros términos, para que los derechos humanos no puedan utilizarse con el fin de eternizar las desigualdades y los obstáculos que el modo de relaciones sociales basado en la acumulación de capital impone, se necesita poner en práctica un conjunto de estrategias antagonistas que nos sirvan de guía o metodología de una acción emancipadora, y esto es lo que lleva al desarrollo de una teoría crítica de los derechos humanos. (Palacios 12)

25 Se entiende acá el derecho natural como todos los preceptos divinos, que son dispuestos por Dios, manifestados por el poder religioso de las instituciones eclesiales. Por esto que en la Edad Media no se utilizaba el término derechos humanos, sino obligaciones o deberes. 
el fin de conquistar sus territorios, dominar su sabiduría ancestral y bautizar en nombre del Dios occidental.

La idea de convivencia solidaria es adoptada por la forma de vida del Zoró, fundamentada en seres humanos que son solidarios, respetuosos y conviven como grupo y comunidad. El énfasis de los derechos está en la humanidad presente en las relaciones comunitarias. Aprendí con ellos a respetar los espacios comunes, el alimento común y compartido, el trabajo comunitario, las ideas y la cosmovisión que hacen parte de su cultura.

\section{Conclusión}

El presente trabajó pretendió sistematizar una experiencia de misión junto al pueblo indígena Zoró e identificar los aprendizajes de esta experiencia. Además de compartir la relevancia de estos aprendizajes en mi vida, la intención también es permitir que estos aprendizajes puedan aportar conocimiento al tema del trabajo con poblaciones indígenas.

El primer aprendizaje tiene que ver con despojarse de la seguridad o armadura del conocimiento adquirido, o sea, desaprender. El encuentro con una cultura diferente, con su propio idioma, costumbres, con una geografía particular y una forma especial de darle sentido a la vida, son situaciones que, al estar en el sitio, de muchas formas rompen con los conocimientos adquiridos previamente.

La experiencia adquirida tiene como referencia la práctica real de la solidaridad, como modelo de convivencia humana. Es posible que esta experiencia sea vista como una utopía, o difícil de replicar, dentro de un mundo marcado por políticas neoliberales que promueven el individualismo y el consumismo salvaje. Los Zoró nos enseñan a apreciar y aprender acerca de otros modos de vivir la vida según modelos de relaciones fraternas y solidarias. Su modo de vida les permite la sobrevivencia en el mundo actual. La experiencia me ha permitido aprender a reconocer al otro y a la otra como a una misma, a tratar a la otra persona como me gustaría que me trataran a mí misma.

Finalmente, hace parte del aprendizaje reconocer y asumir que formamos parte de un sistema excluyente y que marginaliza personas, comunidades y grupos étnicos. Sin embargo, asumir una actitud de defensa de los derechos, de profetismo, de denuncia y de lucha a favor de todas las víctimas de cualquier tipo de atropello, es poner en práctica todos estos aprendizajes.

A modo de conclusión (inconclusa), este artículo presenta algunas dimensiones de la misión como la solidaridad y la promoción de los derechos humanos. Sin embargo, la misión no puede ser entendida desde estos dos principios solamente; existen otras dimensiones de la misión en la que yo también participé, tales como el apoyo a las luchas por territorio, la conservación de su identidad, la educación, el diálogo intercultural, etc. El aprendizaje sigue y otros espacios para compartir y aprender están ahí para ser trazados. 
"Maloca": la casa sin divisiones. Aprendiendo junto al pueblo indígena Zoró

la vivencia de la solidaridad y la promoción de los derechos de los pueblos

"Maloca": the house without divisions. Learning along with the Zoró the

experience of solidarity and promotion of the rights of peoples

"Maloca": a casa sem divisões. Aprendendo pelo povo indígena Zoró a expe-

riência de solidariedade e de promoção dos direitos dos povos

Nelise Wielewsky Narloch

\section{Referencias bibliográficas}

Aguirre García, Juan Carlos y Jaramillo Echeverri, Luis Guillermo. "El otro en Lévinas: Una salida a la encrucijada sujeto-objeto y su pertinencia en las ciencias sociales". Revista Latinoamericana de Ciencias Sociales, Niñez y Juventud, Norteamérica 4, 2 (ago. 2011). Web. Recuperado de: http:// revistaumanizales.cinde.org.co/index.php/Revista-Latinoamericana/article/view/395/230

Camps, Victoria. Virtudes Públicas. Madrid: Espasa Calpe, 1990. Impreso.

$V$ Conferencia General del Episcopado Latinoamericano y del Caribe. Documento de Aparecida. Bogotá: San Pablo, 2007. Impreso.

IV Conferencia General del Episcopado Latinoamericano y del Caribe. Documento de Santo Domingo. 1992. Web. Recuperado de: http://www.celam.org/conferencia_domingo.php

Gallardo, Helio. Teoría crítica y derechos humanos. Una lectura latinoamericana. Caracas: Pentagráfica, 2011. Impreso

Juan Pablo II. Carta Encíclica Redemptoris Missio. Vaticano: Libreria Editrice Vaticana, 1990. Impreso.

XVIII Assembléia Geral do Cimi. Conselho Indigenista Missionario. Web. Recuperado de: http://www.cimi. org.br/site/pt-br/index.php?system=news\&action=read\&id=4237

Lacerda, María Conceicao. "Beka Pamakube. Aprendendo com os Zoró: análise da identidade indígena através da experiencia das escolas nas aldeias do povo Indígena Zoró”. Ji Paraná: 2014. En prensa.

Palacios Valencia, Yennesit. "La teoría crítica de los derechos humanos como punto de partida para combatir el derecho penal del enemigo". Métodhos, Revista Electrónica de Investigación Aplicada en Derechos Humanos 3, 4 (ene.-jun. 2013): 8-43. Web. Recuperado de: http://201.147.150.252:8080/jspui/ bitstream/123456789/3438/1/Metodhos4a-1.pdf

Ribeiro, Gustavo Lins. A condicao da transnacionalidade. Brasilia: UNB, 1997. Impreso.

Salvat Boloña y Salas Astrain, Pablo; Ricardo. Derechos humanos. Pensamiento crítico Latinoamericano. Santiago: UCSH, 2005.

Robert, Sylvie. La teología de los consejos evangélicos de la vida consagrada apostólica. Roma: Seminario Teológico, 2011.

Truchero Cuevas, Javier. "Rorty y la solidaridad". Anuario de filosofía del derecho. 25 (2008-2009). Web. Recuperado de: http://dialnet.unirioja.es/descarga/articulo/3134493.pdf 